\title{
Condições de trabalho e repercussões pessoais e profissionais dos envolvidos com a pós-graduação stricto sensu: balanço e perspectivas*
}

Lucídio Bianchetti

Universidade Federal de Santa Catarina

\section{Resumo}

Apesar das críticas ao sistema Capes, não se registram movimentos com potencial de abalá-lo. Manifestações diversas e pesquisa evidenciam que, a despeito de discordâncias, os envolvidos com a pós-graduação (PG) tudo fazem para (re)ingressar ou manter-se no sistema. Constatam-se prejuízos à produção e veiculação do conhecimento e às condições de vida/trabalho daqueles que atuam na PG. No entanto, uma espécie de naturalização parece estar garantindo a manutenção do modelo de avaliação e financiamento, caracterizado mais como uma política de estado do que de governo. Neste texto, além de tratar de algumas destas questões, destacamos avanços decorrentes da implementação desse sistema, bem como o aprofundamento de aspectos que deixam a desejar, em especial nas Ciências Humanas e Sociais.

Palavras-chave: Pós-graduação. Campo-Capes. Trabalho. Produção do conhecimento.

* Uma versão deste texto serviu de base para nossa participação no IV Seminário Internacional sobre Filosofia e Educação. Balanço Crítico e Perspectivas da PG em Educação no Brasil, realizado na Universidade de Passo Fundo - RS, em 19 de maio de 2011. 


\section{Working conditions and personal and professional repercussions upon those involved with stricto sensu graduate studies: review and future perspectives}

Despite criticism of the Capes system, there is no evidence of anything capable of threatening it. Research and various discussions show that, in spite of the disagreements on the subject, those who are involved in graduate courses do everything possible to re-enter the system of remain in it. Losses have been perceived in the production and reporting of knowledge, and the living and work conditions of those involved in graduate courses. Nevertheless, it seems the evaluation and funding model, characterized more as a state than governmental policy, has somehow begun to be considered natural, what has been assuring its continuance. This paper, in addition to addressing some of these issues, highlights advances resulting from the implementation of this system, as well as the intensification of undesirable factors, particularly in the Social and Human Sciences.

Keywords: Graduate Studies. Field-Capes. Work. Production of knowledge.

\section{Condiciones de trabajo y repercusiones personales y profesionales de los involucrados con la pos-graduación stricto sensu: balance y perspectivas}

A pesar de las críticas al Sistema Capes, no se registran movimientos con el potencial suficiente para debilitarlo. Evidencias de investigaciones confirman que, a pesar de las inconformidades, los involucrados con la pos-graduación (PG) hacen de todo para (re)ingresar o mantenerse en el Sistema. Asimismo, se constatan perjuicios en la producción and socialización del conocimiento y en las condiciones de vida and trabajo de los participantes en la PG. No obstante, una especie de naturalización parece estar garantizando el mantenimiento del sistema, caracterizado más como una política de estado que de gobierno. En este texto, además de analizar algunos de estos asuntos, destacamos los avances provenientes de la implementación de este sistema, así como profundizamos en los aspectos limitantes, en especial en las Ciencias Sociales y Humanas.

Palabras clave: Pos-graduación. Campo-Capes. Trabajo. Producción de Conocimiento. 


\section{Contextualização da temática}

Em um conto intitulado La nada, Leonid Andréiev relata o encontro de um homem, que está prestes a morrer, com um enviado do diabo. Confrontado com as opções referentes à vida eterna e contando com as descrições que lhe são feitas, o moribundo fica tentado a optar pelo inferno. Contudo, antes de assinar sua sentença eterna, é assaltado pela dúvida, que o leva a questionar:

“Y el sofrimiento?

- Bah!" - diz o diabólico emissário - "Tanta preocupación por el dolor (...). Cualquier padecimento deja de serlo cuando se convierte en hábito". (Andréiev, 2009, p. 23)

Aqui situa-se uma das questões basilares da temática deste trabalho. Como não sucumbir ao hábito das atentatórias condições no processo de trabalho e como não transigir no direito de realizar-se na condição de pessoas e de profissionais frente à indução, à heteronomia que tem caracterizado o trabalho dos envolvidos com a PG, avaliado e financiado pela Coordenação de Aperfeiçoamento de Pessoal de Nível Superior (Capes) ?' 0 que é necessário e possível fazer para que ganhe materialidade o revolucionar do status quo conforme a divisa do Manifesto do Partido Comunista de 1848, "De cada um conforme suas possibilidades; a cada um conforme suas necessidades"? Como posicionar-se frente à sobreintensificação e à sobre-exploração do trabalho, uma vez que, com a criação e a incorporação das chamadas Novas Tecnologias da Informação e da Comunicação (TIC), somos submetidos, concomitantemente, à maisvalia absoluta e relativa, com a consequente permeabilização das fronteiras entre o espaço/tempo público e privado $?^{2}$ Como aceitar que o nosso trabalho seja submetido a ser medido, predominantemente, por produtos quantificáveis? De que recursos lançar mão para não naturalizar o histórico e socialmente construído, neste caso, de uma política pública, que passa a ser informada, conformada e formatada por um sistema de avaliação e fomento? Enfim, que condições e de que meios deveríamos dispor para

1. A despeito de a avaliação da pós-graduação ser feita pelos pares, não podemos deixar de ter presente que o processo é desenvolvido no contexto de um enquadramento previamente estabelecido e assumido pelos pares. Isto não significa afirmar que não tenha havido mobilizações, interferências no sentido da mudança dos critérios, mas pouco se consegue em termos de fugir do padrão único de avaliação. A respeito da avaliação pelos pares, indicamos análise feita em Bianchetti (2009a). De outra parte, reconhecemos que há conquistas e avanços na Pós-graduação que devem ser creditadas ao sistema de avaliação e fomento da Capes. Em trabalho anterior, dedicamos parte do texto a este aspecto (Bianchetti (2009b). Por fim, a análise do site da Capes (cf. http://www.capes.gov.br), em outra perspectiva, não deixa margem a dúvidas quanto ao sucesso do sistema. Neste texto, no entanto, nos dedicamos a questionamentos, a críticas na direção da temática apontada no título, bem como às vivências e reflexões resultantes de mais de 15 anos de inserção, no sistema, de diferentes formas.

2. Para aprofundar esta questão e perceber que não é uma particularidade dos pesquisadores brasileiros, ver Bianchetti (2010b). De outra parte, sobre a intensificação do trabalho e suas consequências, cf. Dal Rosso (2008) e Schwartz (2005). 
radicalizar na conquista da omnilateralidade, pressuposto para superar o hábito, a banalização daquilo que poderia ser a praxis e, em perspectiva, construir e desenvolver uma outra praxis em cujo contexto seja possível “caçar de manhã, pescar à tarde e fazer poesia à noite"? (Marx; Engels, 1987).

A menção à frase de Marx e Engels (1987), presente no livro A Ideologia Alemã, remete ao fato de que, por mais que os intelectuais orgânicos do sistema vigente se esforcem para mostrar que houve mudanças, e para melhor, não há como deixar de perceber que a "lógica sociometabólica” do capital (Mészáros, 2002) permanece inalterada. Mais sofisticada, porém não menos deletéria. 0 modo de produção capitalista, compreendido como um "processo civilizatório" (lanni, 1992), promove transformações aparentes (Harvey, 1993), visando garantir sua manutenção e domínio por todos os quadrantes e em todas as instâncias. E no nosso caso específico, destaca-se a universidade, cada vez mais semelhante em sua submissão a demandas externas, eivadas de um caráter pragmático e utilitário, com especial destaque para a mercantilização da pós-graduação (Silva Jr., 2005).

É nessa perspectiva que o trabalho daqueles que hoje pensam e fazem a pósgraduação stricto sensu está conformado, induzido por uma série de determinantes que acabam por retirar-lhes a possibilidade de autonomia, mesmo que para isto seja necessário adjetivá-la como relativa, o que na verdade é. Ocorre que, embora a "agência de fomento e avaliação" prefira dispensar as críticas e apropriar-se dos resultados pois são estes que, na condição de produtos, contribuem para a melhoria nos rankings e o retorno a partir de patentes - é impossível deixar de ter presente as consequências de uma avaliação homogênea para realidades e áreas de conhecimento heterogêneas. Não sendo levadas em conta as assimetrias de níveis de desenvolvimento regionais e entre áreas (e mesmo intra-áreas), torna-se difícil deixar de questionar: o que, daquilo que fazemos, é passível de patenteamento? 0 que seria possível, por exemplo, patentear da produção e do pensamento de Paulo Freire? E se nada o for, por que investir, perguntariam os burocratas? Parece ser esta a perspectiva daqueles que insistentemente questionam a validade daquilo que é produzido por aqueles/as que pesquisam e atuam nas Ciências Sociais e Humanas.

Estas, entre tantas questões, fazem parte do universo e povoam o dia-a-dia daqueles/as que se dedicam à pós-graduação. E desafiar-se e ser desafiado/a a fazer um balanço crítico implica não deixar de ter presente que analisar a pós-graduação, na perspectiva temporal, obriga a que se tenha presente aquilo que se pretendia; como o campo-Capes veio sendo apropriado e quais são as perspectivas que se desenham no horizonte, seja de continuidade daquilo que estamos vivenciando, seja das possibilidades de novos direcionamentos. 


\section{Criação e constituição do campo-Capes: do ontem para os dias atuais}

Julgamos desnecessário dedicar espaço e tempo no texto para falar da criação e da constituição daquilo que denominamos de campo ${ }^{3}$-Capes ${ }^{4}$. Contudo, indicamos momentos que podem ser considerados pontos de inflexão da forma de organização e de funcionamento desse órgão, fazendo uma breve retomada de alguns momentos marcantes da trajetória da Capes que servirão de pano de fundo para as análises dos próximos itens.

A inicialmente denominada Campanha de Aperfeiçoamento de Pessoal do Ensino Superior surge em 1951, com a incumbência de erradicar o contingente de professores não titulados que atuavam nas IES públicas. Anísio Teixeira (1900-1971), cofundador, secretário e primeiro presidente da Campanha, acreditava que por meio da pósgraduação (PG), promovida pelo órgão, seria possível transformar ou reconstruir a universidade brasileira (Mendonça, 2003). No entanto, poderíamos afirmar que é somente a partir do golpe militar de 1964 que a Capes, já não mais como uma Secretaria do então Instituto Nacional de Estudos e Pesquisas Pedagógicas (INEP), passa a fazer parte de um conjunto de órgãos, sistemas e frentes, mobilizado pelos militares a fim de alcançar o almejado "Brasil grande".

Pela metade da década de 1970, o órgão recebeu dotações orçamentárias mais substanciosas e incumbências mais desafiadoras no sentido de formar professores de altas habilidades em todas as áreas, subsidiando-os nos seus mestrados e doutorados principalmente no exterior, dada a incipiência da pós-graduação stricto sensu no Brasil. É também nesse momento que são criadas as associações específicas das áreas, a fim de disponibilizar os pareceristas ad hoc e membros de comissões que o órgão necessitava para distribuir as bolsas e canalizar os recursos de que dispunha a fim de fomentar a pós-graduação. É desta decisão que irá brotar uma das mais bem sucedidas iniciativas da Capes: a avaliação pelos pares, estratégia consagrada e que reforça a legitimidade das suas políticas e iniciativas perante a comunidade científica do país.

É da década de 1970 também a responsabilização atribuída e assumida pela Capes de elaborar, coordenar e implementar os Planos Nacionais de Pós-graduação (PNPGs). Estes são documentos que trazem diagnósticos da pós-graduação e sintetizam as diretrizes que norteiam as políticas públicas de qualificação de pessoal em nível de mestrado e doutorado. Foram editados a cada seis anos até o V PNPG (2005-2010),

3. Bourdieu (2005) dedica um capítulo do livro 0 poder simbólico para explicitar os conceitos de campo e habitus.

4. Cf. Bianchetti (2009a), em cujo texto desenvolvemos esta conceituação, explicitando como a Capes pode ser apreendida como um campo na acepção bourdieana. 
sempre voltados para determinadas iniciativas, que catalizam e dinamizam seja a atuação do órgão, seja a destinação de recursos. A partir do VI PNPG, a projeção de metas passou a ser mais a longo prazo (2011-2020), sendo que para este as prioridades, entre outras, são: melhorar a organicidade com as FAPs (Fundações Estaduais), radicalizar na indução do mestrado profissionalizante, qualificar e melhorar a atuação da Capes voltada à Educação Básica, etc.

Ainda em termos de histórico, digna de menção é a inflexão, ou até pode-se falar em quebra paradigmática (utilizando uma expressão de Kuhn), ocorrida em meados da década de 1990, mais precisamente no triênio de avaliação que vai de 1996 a 1998. Uma das mudanças anunciadas é a passagem da "formação de professores" para a "formação de pesquisadores". Porém, o que a comunidade científica em geral e cada um dos/as envolvidos/as com a pós-graduação stricto sensu em particular passou a sentir no seu cotidiano de trabalho foi a efetiva indução no sentido de diminuição do tempo de titulação de mestrados e doutorados, exigências sem precedentes quanto à produtividade dos docentes e discentes, controle, regulação mais rígida da Capes no/do dia-a-dia dos programas. Enfim, toda uma série de medidas que acabaram enquadrando a pós-graduação no contexto das exigências que buscavam inserir o país no primeiro mundo da produção da ciência.

Daí por diante passou-se a perceber que já não se estava mais frente a uma política de um governo, mas a uma política de estado, pois, independentemente de quem veio assumindo o comando da nação, mantiveram-se as diretrizes heterônomas do sistema Capes de avaliação e financiamento, sendo radicalizadas no sentido da melhoria dos indicadores e uma clara continuidade e prevalência da perspectiva quantitativista. E, sem dúvida, abre-se margem para que se reconheça o sistema - e, por parte dos representantes dos órgãos governamentais, há motivos para vanglória -, em função dos resultados positivos alcançados (cf. http://www.capes.gov.br). Paralelamente a estas conquistas institucionais, que inclusive evidenciam o quanto se está avançando na integração do Brasil à "agenda globalmente estruturada para a educação" (Dale, 2001) ou à "nova ordem educacional" (Antunes, 2008) ou ainda na "direção de um PhD global" (Nerad; Heggelund, 2008), não há como ignorar uma série de decorrências negativas ou subprodutos, induzindo a atitudes e posturas que são tomadas frente à escolha por estar incluído no sistema ou os preços pagos por estar fora, trazendo repercussões que serão objeto de análise nos próximos itens. 


\section{A condição atual de pertença ao sistema Capes}

Pelas constatações anteriores e os aspectos e análises que aparecerão no próximo item, uma questão óbvia é passível de ser levantada: se a inclusão no sistema Capes de avaliação e financiamento, apesar dos seus inegáveis aspectos positivos, interfere tanto nas condições de vida/trabalho quanto na produção e veiculação do conhecimento por parte dos envolvidos com a pós-graduação, o que estaria por trás seja da postura dos professores/orientadores, sejam programas e instituições, de tudo fazerem para ingressar, manter-se ou reingressar no sistema?

Do ponto de vista dos aspectos positivos, é imperioso reconhecer que, num sistema tão jovem quanto é o da pós-graduação stricto sensu brasileira, estar em condiç̃̃es de fomentar e avaliar mais de quatro mil cursos, de titular anualmente mais de 40 mil mestres e 10 mil doutores e de recentemente também ter-se aberto para contribuir com a Educação Básica, entre outras conquistas, é algo digno de nota. Somente na área de Educação, por exemplo, passou-se de meados da década de 1960 para os dias atuais de um (1) curso de pós-graduação stricto sensu para mais de 110 programas inseridos, avaliados e fomentados no/pelo sistema.

Porém, para fazermos uma análise na qual não se descure desses aspectos, mas se leve em conta os custos dessa inclusão no sistema, talvez a forma mais adequada seja fazer um pequeno desvio e procurar apreender o microssistema Capes, no contexto do macrossistema, isto é, o modo de produção vigente. E isto pode ajudarnos a compreender o porquê, a despeito de tantas críticas, persiste-se nos esforços para o ingresso, a manutenção ou a reinserção no sistema.

A literatura e as pesquisas ${ }^{5}$ que estamos fazendo apontam predominantemente para aspectos negativos dessa forma heterônoma de avaliação e fomento que torna preponderante os indicadores de quantificação, controle, regulação e classificação. De outra parte, a disponibilização de uma poderosa infraestrutura materializada nas TIC propiciou

5. Iniciamos em 2002, a partir de Edital Universal do CNPq, juntamente com Ana Maria Netto Machado, pesquisa intitulada "Orientação/escrita de dissertações e teses em questão: produção científica \& estratégias de orientadores e coordenadores de PPGEs". Entre os anos de 2008 a 2010 demos continuidade à pesquisa, na condição de Pesquisador Produtividade do CNPq, com o projeto: "Pesquisadores sob pressão. Pós-graduação, produção/veiculação do conhecimento e emergência de uma nova temporalidade". Atualmente, após período de um ano (2009) em que, em função do estágio pós-doutoral na Universidade do Porto - Portugal, avançamos em um projeto por meio do qual fizemos um comparativo entre o Modelo Capes e o Processo de Bolonha, estamos continuando a pesquisa na condição de Pesquisador Produtividade 1C, com o projeto: "Pesquisadores sob pressão: possibilidades e limites do trabalho (do) intelectual na pósgraduação em educação em tempos de pesquisa administrada" (2011-2014). No que diz respeito à literatura, o texto de Trein e Rodrigues (2011) pode ser considerado uma boa síntese daquilo que está ocorrendo nos programas de PG e na academia em geral. 
condições para que demandas novas fossem inseridas no processo de trabalho na pósgraduação, de tal forma que as categorias de espaço/tempo foram completamente redimensionadas. Como dizia um dos nossos entrevistados: "o espaço não é mais o problema para executar tarefas e o tempo torna-se mais denso, tenso e intenso". Outro ressaltou uma das consequências dessa aceleração: "A velocidade não rima com qualidade". Estas e tantas outras questões que se processam no espaço-tempo reduzido do sistema Capes somente podem ser entendidas no contexto mais amplo, da busca de melhorar rankings, posições e ampliar o poder de barganha do país no mercado mundial. E este é informado, conformado, formatado pela lógica própria do sistema capitalista, que paradigmaticamente opera pela sistemática da inclusão e exclusão (Bianchetti; Correia, 2011) como sua forma própria. Nas palavras de Mészáros (2006, p. 263), “nenhuma sociedade pode perdurar sem seu sistema próprio de educação"; assim, cabe perguntarmo-nos como o microssistema Capes pode ser compreendido, justificado, inserido no contexto do sistema macro. É o próprio Mészáros que nos dá algumas pistas:

O caráter único do sistema do capital é manifesto no imperativo estrutural de 'crescer inexoravelmente ou perecer'. Nenhum outro sistema de reprodução sociometabólica em toda a história humana jamais teve qualquer coisa semelhante a essa determinação interna - extremamente problemática - do capital. Essa determinação estrutural também revela a completa falácia socialmente autovantajosa de deturpar a ordem reprodutiva do capital apresentando-a como regra universal instransponível, arbitrariamente projetada para trás, em direção ao longo passado histórico, e para frente, rumo a um futuro capitalista eternizado. Uma regra universal decretada de forma arbitrária e para a qual, conforme o lema bem conhecido dos apologistas do sistema, "não pode haver alternativa', é claro. (Mészaros, 2007, p. 334, grifo nosso).

Aqui talvez tenhamos uma pista para compreender o fato de que, ao estar no sistema, ou nos submetemos a sua lógica ou estamos fora. E ocorre que ser in ou out traz implicações, desde as condições de trabalho individual até a própria posição da Instituição de Ensino Superior (IES) à qual pertencemos. Esta torna-se um elo na corrente da pressão por produtividade, dado que isto a coloca em melhores condições para pleitear verbas, a partir de melhorias nas classificações. Paralelamente a estes aspectos negativos, há os de outra ordem, relacionados às possibilidades de contribuir para a formação e qualificação de pesquisadores e de professores que atuarão em todos os níveis do sistema de ensino, e para uma maior produção e veiculação do conhecimento e todo o leque de vantagens que a condição de pertencimento estende no horizonte. E entre as vantagens em promessa e a realidade das condições adversas é que se situa a contradição entre o "fazer mais e mais rápido" (Barreto; Borges, 2009) 
e fugir da repetição, do 'requentamento' do mesmo artigo, do "turismo de eventos" (Salles, 2010) etc., a partir da compreensão de que o "controle do tempo" (Paquot, 1998) e a autonomia são condições para produzir algo original.

Não há dúvidas de que a vinculação do fomento à avaliação está na raiz das dificuldades ou até dos impedimentos de resistir a essa forma heterônoma, regulatória, controladora, classificadora de funcionamento do sistema, trazendo consequências que interferem na qualidade em largo espectro e permitem ante ou entrever perspectivas em termos de condições de trabalho, de vida e da qualidade do conhecimento produzido e sua veiculação por parte dos envolvidos com a pós-graduação.

\section{Subprodutos (in)desejáveis, porém inevitáveis, de pertença ao sistema Capes}

No cotidiano dos programas de pós-graduação, acaba por predominar uma postura de adesão e de cumprimento às exigências do sistema, fazendo lembrar, em outras circunstâncias e tempo, as denúncias de La Boétie em termos de servidão voluntária ${ }^{6}$ ou de Pereira (2001) no que diz respeito à servidão ambígua?.

A despeito disto, pensamos ser necessário aprofundar o teor das manifestações que se tornam cada vez mais volumosas em termos de publicações. Acreditamos ser necessário que se avance no sentido de fazer algumas distinções, de mapear aquilo de que já dispomos em termos de alcance de metas via avaliação e financiamento do sistema e aquilo que está deixando a desejar ou poderia ser redirecionado ou, ainda, aquilo que deveria ser suprimido, dado que os subprodutos indesejáveis ou os prejuízos deveriam ser relativizados em relação aos benefícios proclamados ou supostos.

Para esta tarefa sabemos ser necessários espaço e tempo a fim de que, coletivamente, se consiga avançar nesta direção de contar com mais elementos e com uma avaliação na qual estejam contemplados os aspectos eliminados ou minimizados pela forma predominante de avaliação vigente ao levar em conta preponderantemente os aspectos quantitativos, classificatórios, regulatórios. De outra parte, seria necessário o mesmo esforço no sentido de evidenciar aspectos nos quais se avançou como resultado do coletivo, apesar de tantos atentados a uma perspectiva mais coletiva de trabalho. Neste sentido, apontaremos alguns elementos ou subprodutos do modelo vigente a título de temáticas que necessitam de aprofundamento para avanços em uma análise que ultrapasse a visão polarizada ou parcial daquilo que é e, em perspectiva, se vislumbra como decorrências no caso da manutenção do status quo.

6. A obra Discurso sobre a servidão voluntária foi escrita por É. de La Boétie (1530-1563).

7. Em sua tese transformada em livro, Gilson R. Pereira analisa o movimento do magistério do estado de São Paulo, utilizando-se desta categoria explicativa. 
Assim, na sequência, analisaremos alguns aspectos que apontam para balanços e perspectivas, subdividindo a exposição em dois subitens: 1. Constatações a destacar e 2. Subprodutos (in)desejáveis. Entre os (in)desejáveis, alguns são inevitáveis no caso de manter-se a atual situação; no subitem, ressaltamos aspectos positivos e outros que causam preocupação e deveriam ser suprimidos ou redirecionados, em nome da necessária busca de um equilíbrio entre quantidade e qualidade.

\section{Constatações a destacar}

Uma das primeiras questões que chama a atenção daqueles que se dedicam a pesquisar as mais variadas manifestações sobre a forma de organização e funcionamento da Capes diz respeito ao fato de que não há movimentos radicais ou iniciativas coletivas no sentido da supressão da avaliação efetuada ou até do próprio sistema Capes. As críticas voltam-se à avaliação, como ela vem sendo levada a efeito. As discordâncias são muitas, e algumas das motivações e efeitos que as produzem serão tema de outro item.

A ninguém ocorre de "pegar em armas" pela supressão da avaliação. Talvez a menção a dois exemplos corrobore ou ajude a entender as críticas à essa forma de avaliação e não à avaliação: al a falta de qualquer tipo de avaliação fez com que a pós-graduação lato sensu se transformasse em um território de ninguém e/ou de todos, a ponto de gradativamente vir caindo em descrédito e de as "empresas educacionais" que foram as primeiras a aproveitar-se do não controle caminharem para a criação de fórmulas engenhosas, para não dizer enganosas, de oferecer a mesma pós-graduação, porém com outra denominação. É o caso de alguns Master of Business Administration (MBA), dos Master of Business Communication (MBC) e assemelhados, transformados na ante-sala dos mestrados profissionalizantes; b) dentre as muitas iniciativas do governo Collor (1990-1992), as quais, segundo ele mesmo, "deixariam a direita furiosa e a esquerda perplexa", na área educacional, vale menção a extinção da Capes lbem como do INEP). No entanto, mal passou-se um mês de vigência do decreto de extinção da entidade, o governo foi obrigado a recriá-la, frente à pressão por parte de IES, associações de reitores, associações científicas e outras entidades, embora sob outra forma jurídica, isto é, como fundação.

Hoje a Capes já não pode ser considerada como política de um governo, mas uma política de estado. E tal é o seu poder que não se pensa em extinção. Fala-se muito na necessidade de mudanças, mas no dia-a-dia das universidades preponderantemente se trabalha para uma melhor classificação, seja das menores unidades, dos programas, 
seja das instituições. A impressão é que a Capes já está incorporada e é operacional, evidenciada por alguns como um mal necessário.

Uma segunda constatação diz respeito ao fato de que uma geração de professores que se titulou e trabalhou no período em que a preocupação era com a formação de professores (até meados de 1996) já se aposentou ou está em vias de; sua época é marcada por despreocupações em relação ao tempo de titulação, opções canalizadas para a formação - seja como mestres ou doutores, seja na formação destes na condição de orientadores. Quer dizer, não estão mais nos programas as pessoas formadas em outra ambiência e que não alcançavam as exigências draconianas que passaram a ser impostas aos programas de pós-graduação para se manterem em boa posição no ranking, nem aquelas que, a duras penas, davam conta das exigências. Com isto, uma das forças de resistência às imposições deixou de existir. Não fosse suficiente isto, os novos doutores que gradativamente vêm credenciando-se nos programas já inseremse, predominantemente, com a mentalidade de quem alcançou o grau de mestre e doutor nesta nova ambiência, na qual estão naturalizadas a cultura da pressa, da produtividade, do "turismo de eventos" (Salles, 2010) e uma longa listagem de subprodutos potencialmente atentatórios à qualidade da formação promovida nos programas.

Uma das decorrências que se pode constatar predominantemente nos programas, está relacionada ao que Kuhn (2000), em A estrutura das revoluções científicas, denominou de período de ciência normal. Em síntese: mesmo havendo manifestações contrárias, a capacidade de resistência é praticamente zerada e passa-se a conceber como normal ou natural aquilo que foi e vem sendo construído.

\section{Subprodutos (in)desejáveis: balanços e perspectivas}

Seja em outros textos de uma perspectiva crítica, seja em órgãos de divulgação oficiais ou oficiosos e no próprio site da Capes, não há como deixar de reconhecer os inúmeros aspectos positivos advindos da atuação do sistema Capes. Kuenzer e Moraes (2005) afirmam que os elogios vêm de todos os lados quando se fala em alcance de metas, de melhoria das classificações etc. Na sequência, apontaremos alguns elementos que demandam reflexões e ações coletivas, seja para manter e radicalizar, seja para lutar visando a supressão ou a necessária modificação do sistema. 


\section{Evidências e perspectivas: Aspectos positivos a destacar}

Com o passar do tempo, a orientação individual vem sendo claramente abandonada, em favor da coletiva. 0 aumento no número de orientandos, as exigências em termos de produção, a necessidade de forjar-se pesquisador e orientador têm obrigado e induzido a trabalhar mais em grupos nas instituições, e a encontrar meios de criar e reforçar redes colaborativas, aspecto que favoreceu a ampliação do número de interlocutores e de meios de veiculação do conhecimento.

Outro aspecto positivo a ressaltar é que, em decorrência da ampliação geométrica do número de cursos e programas de mestrado e de doutorado, mais pessoas têm tido acesso a cursos de pós-graduação. Particularmente o segmento dos professores do ensino fundamental e médio passou a ser incorporado nos programas, visando ampliar sua formação e/ou acessar níveis superiores nos seus planos de carreira. Em um primeiro momento, devido ao pequeno número destes, e particularmente pelas poucas mudanças materiais (salariais) e simbólicas (status), esses novos mestres e doutores não voltavam, ou permaneciam pouco tempo em seus antigos postos de trabalho. À medida que esse número vem aumentando, esta tendência de evasão está sendo revertida e são inúmeros os aspectos positivos da presença de doutores e mestres na educação básica. Emerge nesse contexto uma espécie de desestruturação de uma ordem estabelecida, daquilo chamado "pacto de mediocridade", e a gradativa implementação de uma "relação virtuosa" (Cury, 2004) entre os diversos graus de ensino, uma vez que a aprendizagem da pesquisa na pós-graduação, o desafio à autoria e à socialização do conhecimento passam a fazer parte da ambiência da educação básica.

Um terceiro aspecto positivo a destacar é o fato de passarmos a ter mais pesquisas a partir de recortes mais refinados da complexa realidade educacional. Cada vez teremos mais artigos, dissertações e teses lançando zooms sobre problemáticas que há pouco tempo eram cobertas por olhares panorâmicos. Há poucos anos contávamos com obras de referência, livros-texto e alguns artigos. Hoje, a tendência é tornar-se mais complicado fazer um estado da arte sobre uma temática, não pela falta de material, mas pelo excesso. De um lado, isto pode ser um problema, pois torna-se difícil fazer uma revisão de literatura que esgote uma temática; de outro, será preciso exercitar-se no processo de investigação a fim de, entre tantas fontes, apropriar-se e basear-se das/naquelas que mais contribuem para que uma problemática seja desvelada.

Em quarto lugar, pode-se prever a necessidade de recortes mais qualificados das temáticas, seja pelo tempo reduzido para concluir a pós-graduação, seja para dar conta de subtemáticas que, de pontos de chegada ou de notas de rodapé de um/a pesquisador/a, se tornarão o ponto de partida para outros que acederão à pós-graduação. 
A questão interessante a se observar é o fato de algumas temáticas sequer serem consideradas objeto de pesquisa, e de um determinado ponto em diante começam a 'pipocar' assuntos novos, cada vez mais subdivididos, recortados, refinados, exigindo uma verticalização ${ }^{8}$, pois as análises panorâmicas de há pouco já não se sustentam neste desafio coletivo de avançar no mapeamento de subtemáticas e na produção de conhecimentos novos frente aos desafios cada vez mais complexos do processo educacional.

Em quinto lugar, uma temática que pouca atenção despertava era a relação orientador/orientando, uma vez que se partia do princípio de que esta era uma relação miniaturizada, individualizada do processo ensino-aprendizagem coletivo. E assim sendo, o orientador orientava e o aluno era orientado e isto ocorria em um espaço que mais se aproximava de um confessionário, dado o mistério que cercava esta relação. E pouco ou nada do que acontecia com o pós-graduando repercutia na vida pessoal, profissional e institucional do orientador. Atualmente essa relação está colocada diante de uma nova realidade (Bianchetti; Alves; Espindola, 2010). De um lado, o que acontece com o orientando, do ponto de vista institucional, repercute na vida profissional do orientador e do programa. De outro, cada vez mais, devido à pressão, ao número de orientandos e outras exigências, toma corpo e se amplia a orientação coletiva, lançando-se mão, com mais frequência, da figura do co-orientador e das discussões sobre qualificações, defesas e apresentação de trabalhos em eventos no grupo de pesquisa. Nesse, são feitas muitas experimentações, exercícios antes de efetivamente enfrentar qualquer das fases do ritual de passagem que é cada uma dessas etapas de formação dos pós-graduandos.

Juntamente com a abertura para as questões de ordem acadêmico-institucionais e psicológicas, estão sendo abertos leques de outras, visando compreender o motivo de ser a pós-graduação tão traumática para muitos mestrandos e doutorandos, a ponto de, para alguns, a vida divide-se entre "antes e depois da pós-graduação" (Bitencourt, 2011). Agregamos o fato de que muitas palavras ou expressões que envolvem o ritual remetem à linguagem jurídico-policial: defesa, banca (no Brasil); júri (Portugal); tribunal de tesis (Espanha) etc.

Em síntese, ao ressaltar aspectos positivos relacionados às novas temáticas que estão sendo pesquisadas, por decorrência apontamos para questões que evidenciam, antecipam e até ajudam a entender muitos dos subprodutos indesejáveis, como veremos na sequência.

8. Exemplar, neste aspecto, é a temática de tese de Bitencourt (2011). 


\section{Subprodutos indesejáveis: Vivências e perspectivas}

Um dos primeiros subprodutos da forma de organização e funcionamento do sistema Capes, hoje, poderia ser caracterizado como um dilema shakespeariano: "ser ou não ser" ou, melhor dizendo: fazer parte ou não pertencer aos quadros institucionais da pós-graduação, eis a questão! Seja qual for a forma de analisar, o pertencimento a um programa de pós-graduação é um problema de intensidades e repercussões diversas. Se pensarmos em IES privadas ou confessionais, onde há programas de pós-graduação, pertencer ou não pode determinar a manutenção do emprego ou a dispensa. 0 vivido e o em perspectiva evidencia que o contingente de pessoas que não estão satisfeitas carece de condições e respaldo para o enfrentamento ou saídas alternativas à via única, fruto da indução do sistema. A busca de saídas individuais por parte de professores por meio do desligamento de programas - saída que pode ser caracterizada como microrresistência, uma vez que a lógica predominante é a da competição, pouco propícia ou impeditiva de saídas coletivas - é um subproduto indesejável e que tende a aprofundar-se.

Um segundo subproduto que podemos considerar indesejável da atual forma de organização e funcionamento do sistema são as constantes mudanças, as quais encontrariam símile literária na obra 0 processo, de Franz Kafka. Ocorre que são tantas e tão variadas as exigências que se abatem sobre professores orientadores, discentes, setores burocráticos, programas de pós-graduação e IES, que acabam dificultando ou até impedindo a realização de um trabalho não premido pelos prazos, os quais garantem o preenchimento do critério de quantidade mas, no mínimo, mantêm a interrogação sobre a qualidade. Assim, como na perspectiva kafkiana, o sujeito fica subjugado a uma situação em que se insere sem, contudo, entender essa inserção, de tal forma que se materializa o estranhamento, a alienação do processo e do produto daquilo que fazemos, provocando uma plêiade de doenças do trabalho. E frente a estas constatações não será de se estranhar que em breve passemos a tomar conhecimento e talvez parte de processos por "assédio moral" (Hirigoyen, 2009), uma vez que, por mais que façamos, sempre será pouco, e o não alcance de metas desencadeia uma série de represálias resultantes na culpabilização da vítima ou na materialização ameaçadora do adágio bíblico segundo o qual "ao que tiver, ser-lhe-á dado; e ao que não tiver, até aquilo que pensa ter, ser-lhe-á tirado" (Lucas, VIII, 16-18). Afinal, dostoievskianamente falando, acabamos quase compungidos a nos perguntar: qual é o crime que cometemos para merecer tamanho castigo?

0 subproduto anterior nos conecta com o próximo, que poderia ser classificado como um drama com colorações que ultrapassam aquilo que comumente se denomina 
de postura maquiavélica, embora nada se possa imputar a Maquiavel daquilo que se está fazendo hoje. Ocorre que Maquiavel expôs em 0 Príncipe uma verdadeira metodologia e didática de causar estupefação, instrumentalizando a obra a como conquistar e manter as conquistas.

Aquilo que se poderia denominar de maquiavelismo na forma de organização e funcionamento da Capes está relacionado ao fato de que a cada indução somos levados a pensar que se chegou ao limite, que mais do que aquele ponto não é possível se passar em termos de exigências. No entanto, quando metas são alcançadas, impõese outras exigências, ou, utilizando a linguagem de uma autoridade do sistema Capes, sobe-se o sarrafo. E a criatividade nesta área parece não ter limites: houve um período em que era possível contar com mestres em bancas; que formar bancas somente com integrantes do mesmo programa não constituía um problema; que mestres com experiência podiam orientar ou co-orientar; que publicar uma revista somente com artigos de professores do mesmo programa e/ou IES não era endogenia e assim a lista poderia ir se estendendo indefinidamente. Mas a partir de um determinado momento foram feitas novas exigências, e quando os programas se adaptaram, de pouco valia enfatizar nos relatórios o que se havia feito. Assim, o feito já era esperado e, uma vez que todos os programas alcançaram essas metas, era imperioso inserir outras, numa espiral interminável. 0 que é finito, contudo, é a capacidade dos envolvidos com a pósgraduação de se superarem constantemente, embora haja esforços (sobre)humanos para dar conta de cada vez mais exigências ou de tentar ultrapassar a barra que a cada vez é colocada uns centímetros acima.

A junção de plataformas, o cruzamento de informações, o desenvolvimento de softwares de caça ao plágio, o Coleta Capes anual e seu somatório trienal e tantos outros mecanismos que acabam tornando pública a vida privada dos envolvidos com a pós-graduação nos remetem a um mundo orwelliano, no qual o big brother-CAPE", real ou insinuadamente, é onipresente e onisciente (Orwell, 1983), estando em todos os lugares e sabendo de tudo o que ocorre nos programas de pós-graduação. Eis um dos subprodutos que resulta de uma postura heterônoma, indutora e que faz com que, conforme ocorria no Panóptico de J. Bentham (Silva, 2000): todos sintam-se vigiados e acabem fazendo aquilo que explícita ou imaginadamente se pensa que deles se espera. Não é de se estranhar que, a despeito de as áreas de conhecimento serem tão heterogêneas, caberem ou poderem caber em uma plataforma de avaliação que as torna homogêneas. Quando especificidades não são respeitadas, quando diferentes são tratados igualmente, a gangorra funciona...

Mais um dos subprodutos indesejáveis a que estamos fazendo referência decorre não das TIC em si, mas sim do seu labluso. Primeiramente, não vai aqui nenhuma 
crítica às TIC. Muito pelo contrário. Compreendemo-nas como criações, como qualificações humanas objetivadas em softwares e hardwares e que deveriam ser incorporadas para poupar tempo, enfim, para potencializar as capacidades humanas como previa Bacon (1979) no seu Novum Organum, e com destaque na Nova Atlântida, olhando positivamente para as criações que vislumbrava para um futuro breve.

A segunda observação a este respeito refere-se ao fato de que muitos professores orientadores ainda atuantes nos programas de pós-graduação são "imigrantes digitais" (Veen; Vrakking, 2009; Prensky, 2001) e formam, diferentemente dos "nativos digitais", um grupo que resiste ou toma atitudes que os aproxima dos ludditas, no que diz respeito à incorporação e ao uso das TIC. Ocorre que, seja qual for a inserção profissional, não há mais como deixar de fazer parte da sociedade da informação.

Feitas essas constatações, retomamos o fio da argumentação a respeito de subprodutos indesejáveis no que diz respeito à inserção das TIC no trabalho daqueles que se dedicam à pós-graduação. Não há como deixar de reconhecer as facilidades propiciadas pela rede e seus instrumentais. Porém, não há também como deixar de ter presente que a mediação das TIC tem sido mais um dos fatores intensificadores do processo de trabalho.

As TIC, da forma como são utilizadas, acabam por favorecer aquilo que poderia chamar-se de um presentismo eterno. Favorecem o right now, o "tudo ao mesmo tempo, aqui, agora o tempo todo" (Ferreira, 2004), o online. E frente a isto é preciso que se pergunte: como fica a educação que, apreendida em sua totalidade, depende do resgate daquilo que ocorreu no ontem; da construção e transmissão dos conhecimentos produzidos hoje, e do lançamento ao horizonte de perspectivas axiológicas e teleológicas a fim de que o caminhar tenha direção e sentido? E mais: se nossa base de trabalho não for o patrimônio cultural da humanidade, de que outros argumentos vamos lançar mão para legitimar a existência da área de Educação, em particular, e das Ciências Sociais e Humanas em geral? E ter que lutar pela legitimação suprime tempo da práxis, fundamental justificadora da existência das diversas áreas de conhecimento, cada uma delas e no conjunto responsáveis pela felicidade de todos. 0 problema é que devido a sistemáticos ataques à falta de resultados (patentes, royalties...) da pós-graduação em educação, temos que gastar mais tempo para justificar aos outros que somos necessários.

Dentre os subprodutos indesejáveis, mas presentes desde os primórdios da pósgraduação e cada vez mais vigoroso, com perspectiva de aprofundamento, está aquilo que chamaríamos de a colonização da Educação pela Economia. A neoteoria do capital humano tornou vulgar, no sentido latino do termo, a ideia de que a educação é tudo; que a elevação da educação garante ipso facto a elevação da renda; que os males da 
sociedade atual são causados pela falta de educação da população e da incapacidade dela de dar conta dos desafios relacionados à leitura do mundo, à criação das condições para todos inserirem-se, manterem-se ou reinserirem-se no mercado de trabalho. Mas pouco se fala da educação com $\mathrm{E}$, sobre a qual restam espaços exíguos para discutir, já que os olhares estão voltados para a informação e para a aprendizagem daquilo que garantirá, no imediato, o retorno para a necessária produção a qual se visa manter. A distância entre a criação em termos de produtos e de conhecimentos e o seu abandono (Franco, 1997) está cada vez mais exígua, ressaltando a necessidade inerente de descarte, de destruição típica do modo de produção capitalista, a qual visa sua contínua vigência, como chama a atenção Mészáros (2002).

Outro subproduto indesejável refere-se ao fato de que aquilo que fazemos em Educação não é passível de ser fragmentado e transformado em patentes para, pragmática e utilitariamente, trazer retornos, royalties etc. É lícito questionar como seria possível patentear um método, um conceito como os de emancipação, autonomia e conscientização? 0 desiderato, via Educação, é exatamente a perspectiva de totalidade, a capacidade de radicalização da consciência das possibilidades humanas, a aprendizagem da existência de deveres e a necessidade de cumpri-los, paralelamente à defesa intransigente dos direitos.

Em termos de perspectiva, outro aspecto tende a radicalizar-se: a assimetria entre e intra-áreas de conhecimento, fazendo com que algumas sejam mais nobres, rentáveis, necessárias, enquanto outras são meramente toleradas. No horizonte, não havendo freios, veremos cada vez mais materializada a "empresarialização da pedagogia e a pedagogização da empresa”, conforme expressão de Correia (2011).

Pensamos também que não se poderia deixar de relacionar um subproduto indesejável, particularmente para a área de Educação: o mestrado profissionalizante, já implementado e até o doutorado, em perspectiva. Durante muito tempo a área firmemente posicionou-se, pelas suas representações, na defesa de que o mestrado profissionalizante na área de Educação, dado seu objeto, é o mestrado acadêmico. E enquanto a questão esteve relacionada a encaminhamentos, o processo foi barrado. Recentemente foram destacados recursos no orçamento, induzindo o financiamento desta modalidade da pós-graduação. E mais uma vez ficou claro que os recursos representam poderoso indutor, e a área acabou abrindo-se para esta modalidade de pós-graduação. Quanto ao doutorado profissional, em perspectiva, basta verificar em Ribeiro (2008) para perceber que está em gestação.

Outra questão atual e em perspectiva na categoria dos indesejáveis subprodutos do modelo é o fato de os envolvidos com a pós-graduação passarem a fazer uso do chiste, das piadas, das metáforas, das chacotas para referenciar-se ao dia-a-dia do trabalho 
na PG. Evidentemente, nada temos contra o humor no trato de qualquer questão. No entanto, a forma como esta prática vem sendo implementada foi revelada por Freud (1995), ao mostrar como se faz uso deste expediente para a catarse, para o alívio de situações que vão ao limite do suportável, e assim as pessoas encontram válvulas de escape. Ora, o humor, ao mesmo tempo que desempenha esse papel, contribui para que situações indesejáveis acabem tornando-se hábitos, sendo naturalizadas.

Por fim, entre os aspectos indesejáveis do atual modelo, no ápice da pirâmide e com perspectivas de radicalização, está o chamado "produtivismo acadêmico", assunto bastante explorado (Sguissardi; Silva Jr., 2009), mas que teve em Jacoby (1990) o mais antigo denunciador do quanto foi deletério para os campi norte-americanos o "publish or perish" da década de 1960; em Waters (2006), evidenciam-se resultados mais atuais dessa estratégia do "paper substituindo livro". (Chauí, 2003) E destacamos os deletérios para aquilo que se chama de formação e de Educação no pleno sentido. A pressão pelo número de publicações está levando a que se produzam "rotten papers", como diz Duarte Jr. (2010) sobre a qualidade. Porém, é com Evangelista (2006) que encerramos, quando esta, falando a respeito do "publicar ou perecer", faz uma série de jogos com as duas palavras, concluindo com um que aponta para outros tipos de atentados, englobados por esta verdadeira febre que tomou conta dos campi: "publicar pero no morir".

\section{À guisa de conclusão}

No decorrer do texto apontamos a necessidade de ser dono do tempo para pensarse na originalidade da obra. Certamente, uma das principais questões de fundo ou problemática que afeta os envolvidos com os programas de $P G$ hoje diz respeito à exiguidade de tempo para dar conta de um leque infindável de tarefas que vão sendo impostas em termos de quantidade e intensidade. Entre as consequências desse processo insere-se o que consideramos o principal atentado ao trabalho (do) intelectual. Não é de estranhar que Tragtenberg (2004) aponte para a "delinquência dos intelectuais"; que Sokal e Bricmont (1999) falem e denunciem "imposturas intelectuais" e que Wallerestein (2004) fale da "neutralidade dos intelectuais" como um problema, sucedido pela afirmação de Chomsky (2006): o intelectual "tem a responsabilidade de dizer a verdade e denunciar mentiras". Mas como fazer isto no contexto que Adorno (1995) denomina como de "pesquisa administrada", ao deparar-se, na condição de exilado nos EUA, com o modus operandi de fomentar, avaliar, cronometrar as pesquisas? 0 resultado poderia ser outro que não "la retirada de los intelectuales", como analisa Follari (2006)? 
De outra parte, Jacoby (2001, p. 139), avançando na análise dos perversos resultados da forma norte-americana de tratar da pós-graduação e da pesquisa, afirma que "ao longo do século $X X$, os intelectuais vêm migrando para instituições, tornando-se especialistas e professores". E se particularmente no decorrer do século XIX e parte do XX os intelectuais foram temidos, respeitados, perseguidos - lembrar do manifesto J'accuse, de É. Zola, em relação ao Caso Dreyfus -, nas décadas e anos mais recentes, devido à indução a respeito da forma de executar o seu trabalho (fomento, avaliação, prazos...), “os intelectuais nem estão em perigo nem são perigosos" (Jacoby, 2001, p. 151).

Para concluir, tomamos de empréstimo as palavras de Milton Santos, uma vez que não somente concordamos com o seu teor, como achamos que fecham provisoriamente, de uma forma instigante, a reflexão que procuramos fazer sobre a temática da $P G$ brasileira atual e em perspectiva:

0 terrível é que, nesse mundo de hoje, aumenta o número de letrados e diminui o de intelectuais. Não é esse um dos dramas atuais da sociedade brasileira? Tais letrados, equivocadamente assimilados aos intelectuais, ou não pensam para encontrar a verdade, ou, encontrando a verdade, não a dizem. Nesse caso, não se podem encontrar com o futuro, renegando a função principal da intelectualidade, isto é, o casamento permanente com o porvir. (Santos, 2000, p. 20)

\section{Referências}

ADORNO, Theodor. Palavras e sinais: modelos críticos 2. Petrópolis: Vozes, 1995.

ANDRÉIEV, Leonid. La nada. In: TOMAS, Maximiliano. Centos breves para leer en el bus. 14. ed. Barcelona: Literaria, 2009.

ANTUNES, Fátima. A nova ordem educacional. Espaço Europeu de Educação e Aprendizagem ao Longo da Vida: Actores, processos, instituições. Subsídios para debate. Coimbra: Almedina, 2008.

BACON, Francis. Os pensadores. 2. ed. São Paulo: Abril Cultural, 1979.

BARRETO, Francisco César Sá; BORGES, Mario Neto. Novas políticas de apoio à pós-graduação: o caso FAPEMIG-Capes. Ensaio: Avaliação e Políticas Públicas em Educação, Rio de Janeiro, v. 17, n. 65, p. 599-612, out.-dez. 2009.

BIANCHETTI, Lucídio. Os dilemas do Coordenador de Programa de Pós-graduação: entre o burocráticoadministrativo e o acadêmico-pedagógico. In: .; SGUISSARDI, Valdemar (Org.). Dilemas da pós-graduação: gestão e avaliação. Campinas: Autores Associados, 2009a.

. 30 anos do Colégio Brasileiro de Ciências do Esporte. Os desafios para uma Associação Científia e os dilemas dos intelectuais institucionalizados. Revista Brasileira de Ciências do Esporte, Campinas, v. 30, n. 3, p. $13-30$, maio, 2009 b. 
. O Processo de Bolonha e a intensificação do trabalho na universidade: Entrevista com Josep M. Blanch. Educação \& Sociedade, Campinas, v. 31, n. 110, p. 263-285, jan.-mar. 2010.

.; ALVES, Vânia Maria; ESPINDOLA, Isabel Cristina. A relação orientador-orientando na pósgraduação stricto sensu no Brasil: a autonomia dos discentes em discussão. In: SEMINÁRIO DE PESQUISA EM EDUCAC̣ÃO DA REGIÃO SUL, 7., 2010, Londrina. Anais... Londrina: UEL, 2010.

.; CORREIA, José A. In/exclusão no trabalho e na escola: aspectos mitológicos, históricos e conceituais. Campinas: Papirus, 2011.

BITENCOURT, Silvana Maria. Candidatas à ciência: a compreensão da maternidade na fase do doutorado. 2011. Tese (Doutorado em Sociologia Política) - Programa de Pós-graduação em Sociologia Política, Universidade Federal de Santa Catarina, Florianópolis, 2011.

BOURDIEU, Pierre. O poder simbólico. 8. ed. Rio de Janeiro: Bertrand Brasil, 2005.

CHAUÍ, Marilena. A universidade pública sob nova perspectiva. Revista Brasileira de Educação, Rio de Janeiro, ANPEd, n. 24, p. 5-15, set.-dez. 2003.

CORREIA, José Alberto. Construção político-cognitiva da exclusão social no campo educativo. In: BIANCHETTI, Lucídio; . In/exclusão no trabalho e na escola: aspectos mitológicos, históricos e conceituais. Campinas: Papirus, 2011.

CHOMSKY, Noam. A responsabilidade dos intelectuais. In: O poder americano e os novos mandarins. Rio de Janeiro: Record, 2006.

CURY, Carlos Roberto Jamil. Graduação/pós-graduação: a busca de uma relação virtuosa. Educação \& Sociedade, Campinas, CEDES, v. 25, n. 88 (especial), p. 777- 794, out. 2004

DALE, Roger. Globalização e educação: demonstrando a existência de uma “cultura educacional mundial comum" ou localizando uma "agenda globalmente estruturada para a educação"? Educação, Sociedade \& Culturas, Porto, UP/FPCE/CIIE, n. 16, p. 133-169, 2001.

DAL ROSSO, Sadi. Mais trabalho! A intensificação do labor na sociedade contemporânea. São Paulo: Boitempo, 2008.

DOSTOIÉVSKY, Fiodor. Crime e castigo. São Paulo: Martin Claret, 2002.

DUARTE Jr. João Francisco. Rotten papers lou Adiós que yo me voy). In: A montanha e o videogame: escritos sobre educação. Campinas: Papirus, 2010.

EVANGELISTA, Olinda. Publicar ou morrer. In: BIANCHETTI, Lucídio; MACHADO, Ana Maria Netto (Org.). A bússola do escrever: desafios e estratégias na orientação e escrita de teses e dissertações. 2. ed. São Paulo e Florianópolis: Cortez e Editora da UFSC, 2006.

FERREIRA, Simone Lucena. Um estudo sobre a interatividade nos ambientes virtuais da internet e sua relação com a educação: o caso da AllTV. 2004. Dissertação (Mestrado em Educação) - Programa de Pós-Gradução em Educação, Universidade Federal de Santa Catarina, Florianópolis , 2004.

FOLLARI, Roberto Agostin. La retirada de los intelectuales. Perspectiva, Florianópolis, NUP/CED/ UFSC, v. 24, n. 1, p. 341-352, 2006.

FRANCO, Marcelo A. Ensaio sobre as tecnologias digitais da inteligência. São Paulo: Papirus, 1997

FREUD, Sigmund. Os chistes e sua relação com o inconsciente. Rio de Janeiro: Imago, 1995. (Obras completas de Sigmund Freud, v. 8) 
HARVEY, David. A condição pós-moderna. São Paulo: Loyola, 1993.

HIRIGOYEN, Marie-France. Assédio Moral: a violência perversa no cotidiano. 11. ed. Rio de Janeiro: Bertrand Brasil, 2009.

IANNI, Octávio. A sociedade global. São Paulo: Civilização Brasileira, 1992.

JACOBY, Russell. Os últimos intelectuais: a cultura americana na era da academia. São Paulo: EDUSP; Trajetória Cultural, 1990.

O fim da utopia: política e cultura na era da apatia. Rio de Janeiro: Record, 2001.

KAFKA, Franz. O Processo. São Paulo: Companhia das Letras, 1997.

KUENZER, Acácia Zeneida; MORAES, Maria Célia Marcondes. Temas e tramas na pós-graduação em educação. Educação \& Sociedade, Campinas, CEDES, v. 26, n. 93, p. 1341-1363, set.-dez. 2005.

KUHN, Thomas. A estrutura das revoluções científicas. 3. ed. São Paulo: Perspectiva, 2000.

LA BOÉTIE, Étienne. Discurso da servidão voluntária. São Paulo: Brasiliense, 1982.

MAQUIAVEL, Nicolau. O Príncipe. Porto Alegre: L\&PM, 2008.

MARX, Karl; ENGELS, Friedrich. Manifesto do Partido Comunista. 6. ed. São Paulo: Global, 1986.

A ideologia alemã (Feuerbach). 6. ed. São Paulo: Hucitec, 1987.

MENDONÇA, Ana Waleska. A pós-graduação como estratégia de reconstrução da universidade brasileira. Educar em Revista, Curitiba, n. 21, p. 289-308, 2003.

MÉSZÁROS, István. Para além do capital. São Paulo: Boitempo; Campinas: Editora da Unicamp, 2002. A teoria da alienação em Marx. São Paulo: Boitempo, 2006.

O desafio e o fardo do tempo histórico. São Paulo: Boitempo, 2007.

NERAD, Maresi; HEGGELUND, Mimi (Ed.). Toward a Global PhD? Forces \& Forms in Doctoral Education Worldwide. Seattle: University of Washington Press, 2008.

ORWELL, George. 1984. 16. ed. São Paulo: Nacional, 1983.

PAQUOT, Thierry. A arte da sesta. Porto: Campo das Letras, 1998.

PEREIRA, Gilson Ricardo. Servidão ambígua: valores e condição do magistério. São Paulo: Escrituras, 2001.

PRENSKY, Marc. Digital natives, digital immigrants. MCB University Press, v. 9, n. 5, October, 2001. Disponível em: <http://www.marcprensky.com/writing/>. Acesso em: 19 jun. 2010.

RIBEIRO, Renato Janine. Doctoral Education in Africa, South America, and Mexico. Brazil. In: NERAD, Maresi; HEGGELUND, Mimi (Ed.). Toward a Global PhD? Forces \& Forms in Doctoral Education Worldwide. Seattle: University of Washington Press, 2008. p. 131-145.

SALLES, João. Notas sobre a filosofia no Brasil. Cult, São Paulo, v. 13, n. 151, p. 71-73, 2010.

SANTOS, Milton. Por uma outra globalização: do pensamento único à consciência universal. 3. ed. Rio de Janeiro: Record, 2000.

SCHWARTZ, Yves. Trabalho e saúde: construindo outros modos de gestão. Tradução de Anna Luiza Telles Kirsch. In: CONGRESSO BRASILEIRO DE CIÊNCIAS SOCIAIS E HUMANAS EM SAÚDE DA ABRASCO, 3., 2005, Florianópolis. Anais... Florianópolis: ABRASC0, 2005. 
SGUISSARDI, Valdemar; SILVA Jr., João dos Reis. Trabalho intensificado nas federais: pós-graduação e produtivismo acadêmico. São Paulo: Xamã, 2009.

SILVA Jr., João dos Reis. A racionalidade mercantil da pós-graduação: a produção da ciência pragmática e do individualismo profissional. In: QUARTIERO, Elisa Maria; BIANCHETTI, Lucídio (Org.). Educação corporativa: mundo do trabalho e do conhecimento: aproximações. São Paulo: Cortez, 2005.

SILVA, Tomaz Tadeu da. 0 panóptico. Belo Horizonte: Autêntica, 2000.

SOKAL, Alan; BRICMONT, Jean. Imposturas intelectuais: o abuso da ciência pelos filósofos pósmodernos. Rio de Janeiro: Record, 1999.

TRAGTENBERG, Maurício. Sobre educação, política e sindicalismo. 3. ed. São Paulo: Editora UNESP, 2004.

TREIN, Eunice; RODRIGUES, José. 0 canto de sereia do produtivismo científico: o mal-estar na academia e o fetichismo do conhecimento-mercadoria. Universidade \& Sociedade, Brasília, ANDES, v. 20, n. 47, p. 123-132, fev. 2011.

WALLERSTEIN, Imanuel. Intelectuais: neutralidade de valores em questão. In: O declínio do poder americano. Rio de Janeiro: Contraponto, 2004.

WATERS, Lindsay. Inimigos da esperança: publicar, perecer e o eclipse da erudição. São Paulo: Editora UNESP, 2006.

VEEN, Win; VRAKKING, Ben. Homo Zappiens: educando na era digital. Porto Alegre: Artmed, 2009.

Recebido em julho de 2011.

Aprovado em outubro de 2011.

Lúcidio Bianchetti, doutor em Educação pela PUC/SP, com estágio pós-doutoral na Universidade do Porto, Portugal. Professor Associado no Centro de Ciências da Educação da UFSC, ex-Coordenador do PPGE/UFSC, Pesquisador Produtividade em Pesquisa 1C do CNPq; líder do grupo de pesquisa Trabalho e Conhecimento na Educação Superior - TRACES. Última obra: BIANCHETTI, L.; CORREIA, J. A. In/exclusão no trabalho e na educação. Campinas: Papirus, 2011. E-mail: lucidio.bianchettiblapq.cnpq.br 